\title{
Mutation analysis and prenatal diagnosis of a Chinese family with Fanconianemia
}

\author{
Zhuwen Gong, Qigang Zhang, Xuefan Gu \\ Department of Pediatric Endocrinology and Genetic Metabolism, Xinhua Hospital, Shanghai Jiao Tong University School of \\ Medicine, Shanghai Institute for Pediatric Research, Shanghai, China.
}

Correspondence: Xuefan Gu. Address: Department of Pediatric Endocrinology and Genetic Metabolism, Xinhua Hospital, Shanghai J iao Tong University School of Medicine, Shanghai Institute for Pediatric Research, 1665 Kongjiang Rd,

Shanghai, China. Email: gu_xuefan@163.com

Received: October 29, 2013

Accepted: December 17, 2013

Online Published: December 18, 2013

DOI : $10.5430 / \mathrm{jhm} . \mathrm{v3n} 2 \mathrm{p} 24$

URL: http://dx.doi.org/10.5430/jhm.v3n2p24

\section{Abstract}

Fanconi anemia (FA) is a rare genetic blood disorder. Because there are at least 15 genetic subtypes that are associated with its development, and large deletions, duplications, or sequence variations are frequently found in some of these genes, customary genetic testing for FA is complicated and time-consuming. Therefore, we used the diagnostic result of a Chinese boy with Fanconi anemia by the next generation sequencing (NGS) as the reference, we confirmed the mutations in him, his father and pregnant mother using Sanger sequencing technique and performed the prenatal diagnosis to the fetus. A heterozygous nucleotide deletion c.989_995del7 (p.H330LfsX2) and nucleotide substitution c.3971C>T (p.P1324L) in FANCA gene were detected in the patient. Further analysis confirmed that the p.H330LfsX2 was derived from his mother and the p.P1324L from his father. As for the fetus, both of the same parental mutations were detected in amniotic fluid and cultured amniotic fluid. Our result shows that NGS combined with Sanger sequencing greatly improve the speed of prenatal diagnosis of FA.

\section{Key words}

Prenatal diagnosis, Next generation sequencing, FANCA, Fanconi anemia

\section{I ntroduction}

Fanconi anemia (FA) is an inherited disorder characterized by diverse defects, including progressive pancytopenia, hyperpigmentation, skeletal malformations, small stature, hematologic malignancies and solid tumor ${ }^{[1]}$. Currently, FA shows a genetic heterogeneity, using cell fusion and complementation analysis, with 15 defined genes corresponding for FA complementation groups: FANCA, FANCB, FANCC, FANCD1, FANCD2, FANCE, FANCF, FANCG, FANCI, BRIP1, FANCL, FANCM, PALB2, RAD51C, SLX ${ }^{[2]}$. Fourteen of above genes are autosomal recessively inherited while FANCB is inherited in an $\mathrm{X}$-linked manner.

Because 15 subtypes genes are linked to FA, and there is a variety of mutant forms in each gene ${ }^{[3]}$, such as large deletions or duplications, missense and frameshift mutations, it is a challenge to make molecular diagnosis. The Sanger sequencing approach we currently used for diagnosis of FA is time-consuming and costly, especially for pregnant women with a classification unknown FA proband. The rapid and accurate prenatal diagnosis will provide a chance to parents to have a 
healthy neonate. We described here a successful prenatal diagnosis to a Chinese pregnant woman with a FA proband by combining the next-generation sequencing and regular DNA sequencing approaches.

\section{Materials and methods}

\subsection{Patients}

A male patient, 4 years old, has been diagnosed of FA for one year. The patient was born to a healthy non-consanguineous family with 40 gestational weeks. The patient's height was $112.2 \mathrm{~cm}$ (p50), and weight was $20 \mathrm{~kg}$ with unremarkable physical urological examination. His initial results of blood cell count were as follows: white blood cell $2.73 \times 10^{9} / \mathrm{L}$, hemoglobin $58 \mathrm{~g} / \mathrm{L}$, platelets $20 \times 10^{9} / \mathrm{L}$. Bone marrow examination showed bone marrow failure. No family members had similar symptoms to the patient. At the time, the patient's mother was 14 weeks pregnant.

\subsection{Genomic DNA preparation}

Informed consent for the study was obtained from the patient's parents. Peripheral venous blood from the proband and his parents was collected in tubes containing EDTA. Amniotic puncture was performed at 17th week of pregnancy according to the requirement of prenatal diagnosis. Genomic DNA from peripheral blood leukocytes, amniotic fluid cell and cultured amniotic fluid was extracted by TIANGEN RelaxGene Blood DNA System.

\subsection{DNA sequencing analysis}

Patient's next-generation sequencing was performed by Shanghai Genesky Biotechnology Co., Ltd. We used software ${ }^{[4-6]}$ to check the mutations in all FA genes and a low-frequency frameshifts and a truncating mutation in FANCA gene were considered as pathogenic compound mutations.

\subsection{PCR amplification and Sanger sequencing}

According to the results of next-generation sequencing, potential mutations were verified by Sanger sequencing. Reaction

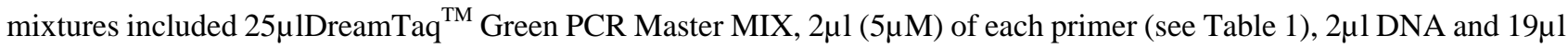
nuclease-free water. The amplification was carried out as follows: denaturation at $95^{\circ} \mathrm{C}$ for $5 \mathrm{~min}$, followed by 33 cycles of denaturation at $95^{\circ} \mathrm{C}$ for $40 \mathrm{~s}$, annealing at $58^{\circ} \mathrm{C}$ for $40 \mathrm{~s}$, extension at $72^{\circ} \mathrm{C}$ for $50 \mathrm{~s}$, and a final extension at $72^{\circ} \mathrm{C}$ for 10 $\min$.

Table 1. Primers for Amplifying Sequences of FANCA

\begin{tabular}{lll}
\hline Exon & Sense primer & Anti-sense primer \\
\hline FANCA-11 & CACAGTTTGTGCTGGGATTG & GGACCCAGTCTCTGGTTCAA \\
FANCA-40 & ATGTCCAGAGTTGCCTGAGC & GGTGATGCCAAGGGATACTG \\
\hline
\end{tabular}

\section{Results}

\subsection{I dentification of FANCA gene mutations in patient}

Two potential heterogeneous mutations were found in the FANCA gene from the patient by Sanger sequencing those were consistent with the found by the next-generation sequencing: one mutation has been reported (HGMD) and the other was a small fragment deletion ${ }^{[7]}$. The reported mutation was c.3971C $>$ T (p.P1324L) in exon 40 (see Figure 1), and the frameshift mutation was c.989_995del7 (p.H330LfsX2), in exon 11 (see Figure 2). The patient's father carried a 
heterozygous c.3971C>T (p. P1324L) mutation and the mother had a heterozygous c.989_995del7 (p.H330LfsX2) mutation.

\subsection{Prenatal diagnosis}

DNA sequencing confirmed the fetus had two heterozygous mutations c.3971C>T (p.P1324L) (see Figure 1) and c.989_995del7 (p.H330LfsX2) (see Figure 2) in the FANCA gene. The p.P1324L was inherited from father and p.H330LfsX2 from mother.

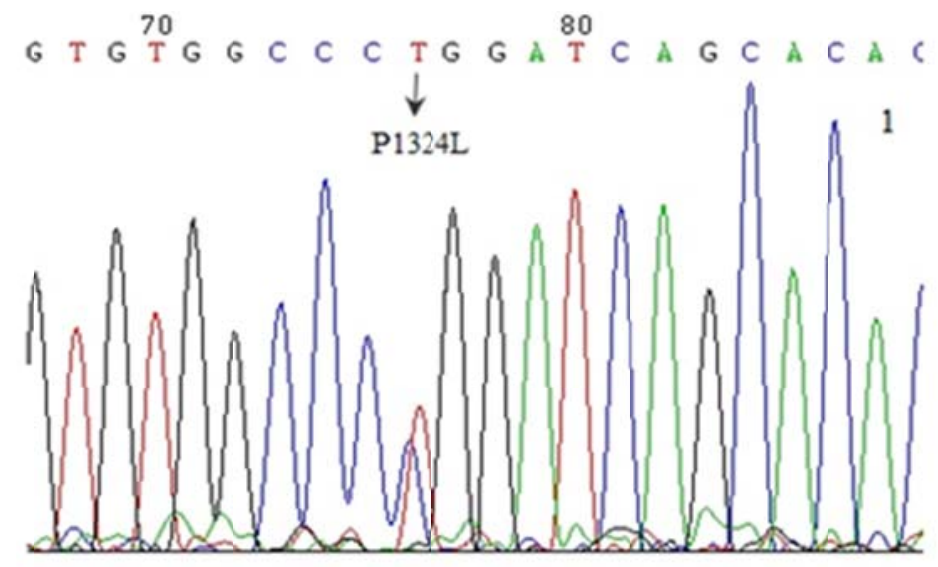

Figure 1. Sequencing results of the FANCA gene show p. P1324L

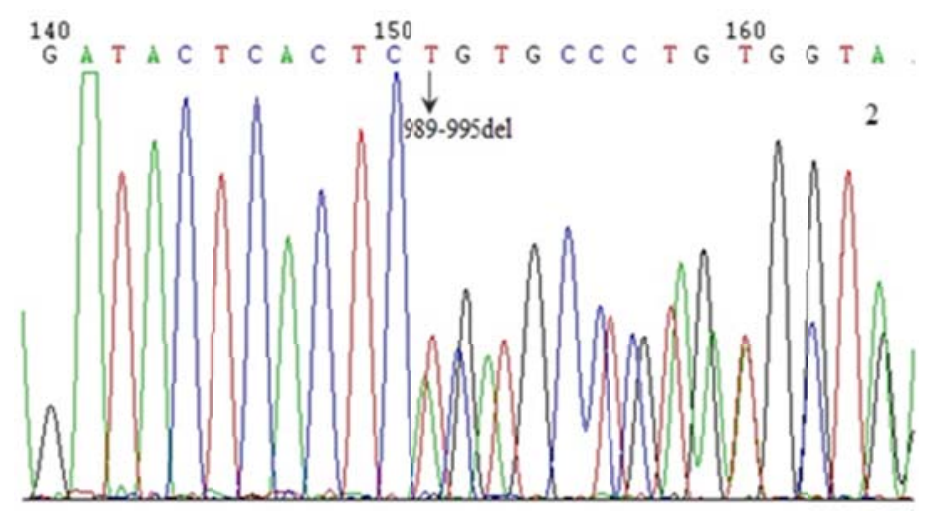

Figure 2. Sequencing results of the FANCA gene show p. H330LfsX2

\section{Discussion}

FA is usually diagnosed according to clinical presentations and chromosome breakage test. The chromosome breakage testing is used widely in detection of amniotic cells, chorionic epithelium cells and fetal blood cells, so it can be used for prenatal diagnosis ${ }^{[8]}$. Though chromosome breakage test is highly specific to the diagnosis of FA, it sometimes gives in false-negative results, similar to those observed in cases of somatic mosaicism patients ${ }^{[9]}$. Therefore, molecular testing is a preferred method for FA diagnosis ${ }^{[2]}$.

The fifteen genetic subtypes of FA have been distinguished as FA-A, -B, -C, -D1, -D2, -E, -F, -G, -I, -J, -L, -M, -N, -O, and -P. The majority of patients belong to the subtypes A (60\%-70\%), C (10-15\%), or G (10\%), and the prevalence of the remaining 12 subtypes is between $1 \%$ to $5 \%{ }^{[10,11]}$. There are variable mutational sites covering the entire FA gene, so it is 
a challenge to genetic diagnosis, especially for a pregnant mother when the proband's molecular diagnosis is unclear. The molecular diagnosis of FA usually uses western blot analysis, immunoprecipitation, RT-PCR or whole FA gene exons sequencing combined with MLPA ${ }^{[10,12]}$. These methods can effectively detect protein expression, point mutations and large fragment deletion/duplications, but it often requires several methods used in combination. Therefore, the diagnosis of FA becomes complicated and time-consuming. The large amounts of sequence-data output pose a bioinformatics challenge for the clinical laboratory if the patient is etiology unknown or unclassified ${ }^{[13]}$.

In this study, when the proband's mother came to our hospital she was already 14 weeks pregnant, so prenatal diagnosis was needed urgently. Disease like FA with severe genetics heterogeneity, it is difficult to identify all the diverse mutations in a short period of time by traditional DNA analysis. So we considered NGS as a screening method and used the result of the patient tested by this method as reference, we first checked the FA subtype gene mutations in a large number of target genes and then verified potential mutations in the patient and his parents by Sanger sequencing. Compared to the current applications of NGS in FA ${ }^{[7,14,15]}$, we combined the NGS and Sanger sequencing to speed up the processing of molecular diagnosis. The total turn round time of the diagnosis of FA was reduced from regular 4 weeks to 2 weeks that provide enough time to the pregnant mother to make decision to her fetus. The parents made decision of abortion according to the positive result, unfortunately we could not obtain the aborted fetus due to most traditional Chinese would not let their loss was disturbed. Otherwise, we should verified the mutations in fetus to clarify our prenatal diagnosis.

In conclusion, using the next-generation sequencing combined with Sanger sequencing can reduce the time of sequencing and can quickly find abnormal mutational sites. It greatly improves the detection speed and provides the reliability of prenatal diagnosis.

\section{Conflict of interest}

All authors declare no conflict of interest.

\section{Acknowledgments}

This study was supported by Key Project of Shanghai Science Commission (11dz1950300) and National Key Technology R\&D Program (2012BA109B04).

\section{References}

[1] Auerbach D. Fanconi Anemia and its Diagnosis. Mutat Res. 2009; 668: 4-10. PMid:19622403 http://dx.doi.org/10.1016/j.mrfmmm.2009.01.013

[2] Lee HJ, Park S, Kang HJ, et a1. A case report of Fanconi anemia diagnosed by genetic testing followed by prenatal diagnosis. Ann Lab Med 2012; 32: 380-384. PMid:22950077 http://dx.doi.org/10.3343/alm.2012.32.5.380

[3] Morgan NV, Tipping AJ, Joenje H, Mathew CG. High frequency of large intragenic deletions in the Fanconi anemia group a gene. Am J Hum Genet 1999; 65: 1330-1341. PMid:10521298 http://dx.doi.org/10.1086/302627

[4] Li H, Durbin R. Fast and accurate short read alignment with Burrows-Wheeler transform. Bioinformatics. 2010; 26: 589-595. PMid:20080505 http://dx.doi.org/10.1093/bioinformatics/btp698

[5] Li H, Handsaker B, Wysoker A, Fennell T, Ruan J, Homer N, et a1. The sequence alignment/map format and SAMtools. Bioinformatics. 2009; 25: 2078-2079. PMid:19505943 http://dx.doi.org/10.1093/bioinformatics/btp352

[6] Koboldt DC. Chen K, Wylie T, Larson DE, McLellan MD, Mardis ER et al. VarScan: variant detection in massively parallel sequencing of individual and pooled samples. Bioinformatics. 2009; 25: 2283-2285. PMid:19542151 http://dx.doi.org/10.1093/bioinformatics/btp373

[7] Zheng Z, Geng J, Yao RE, Li C, Ying D, Shen Y et al. Molecular defects identified by whole exome sequencing in a child with Fanconi anemia. Gene. 2013; 10:295-300. PMid:23973728 http://dx.doi.org/10.1016/j.gene.2013.08.031

[8] Zao YR, Shao ZH. Research progress in pathogenesis and diagnosis of Fanconi anemia. Chin J Pra Med. 2004 ; 24 : $370-371$.

[9] Soulier J, Leblanc T, Larghero J , Dastot H, Shimamura A, Guardiola P et a1. Detection of somatic mosaicim and classification of Fanconi anemia patients by analysis of the FA/BRCA pathway. Blood. 2005; 105: 1329-1336. 
PMid:15383454 http://dx.doi.org/10.1182/blood-2004-05-1852

[10] Gille JJ, Floor K, Kerkhoven L, Ameziane N, Joenje H, de Winter JP. Diagnosis of Fanconi Anemia: Mutation Analysis by Multiplex Ligation-Dependent Probe Amplification and PCR-Based Sanger Sequencing. Anemia. 2012; 603253. PMid:22778927

[11] YU SJ, ZHAO WL. Advances in research on pathogenic mechanism of Fanconi anemia. J DiagnConceptesPract 2010; 9: 285-288.

[12] CHEN F, PENG GJ, ZHANG KJ, HU Q, ZHANG LQ, LIU AG. FANCA gene mutation ayalysis in Fanconi anemia patients. Chin J Hematol. 2005; 10: 616-618.

[13] Voelkerding KV, Dames SA, Durtschi JD. Next-Generation Sequencing: From Basic Research to Diagnostics. Clin Chem. 2009; 55: 641-658. PMid:19246620 http://dx.doi.org/10.1373/clinchem.2008.112789

[14] Knies K, Schuster B, Ameziane N, Rooimans M, Bettecken T, de Winter J et a1. Genotyping of Fanconi Anemia Patients by Whole Exome Sequencing: Advantages and Challenges. PLoS One. 2013; 7: e52648. PMid:23285130 http://dx.doi.org/10.1371/journal.pone.0052648

[15] Ameziane N, Sie D, Dentro S, Ariyurek Y, Kerkhoven L, Joenje H, et a1. Diagnosis of Fanconi Anemia: mutation analysis by next-generation sequencing. Anemia. 2012; 2012:132856. PMid:22720145 http://dx.doi.org/10.1155/2012/132856 